\title{
Effect of filling technique on the bond strength of methacrylate and silorane-based composite restorations
}

\section{Fernanda Weingartner MACHADO(a) \\ Fernanda Blos BORGES(b) \\ Maximiliano Sérgio $\mathrm{CENCI}^{(a)}$ \\ Rafael Ratto de MORAES(a) \\ Noéli BOSCATO(a)}

(a) Universidade Federal de Pelotas - UFPel, School of Dentistry, Graduate Program in Dentistry, Pelotas, RS, Brazil.

(b) Private Practice, Pelotas, RS, Brazil.

Declaration of Interests: The authors certify that they have no commercial or associative interest that represents a conflict of interest in connection with the manuscript.

\section{Corresponding Author:}

Noéli Boscato

E-mail:noeliboscato@gmail.com

DOI: 10.1590/1807-3107BOR-2016.vol30.0044

Submitted: Oct 01, 2015

Accepted for publication: Jan 19, 2016

Last revision: Feb 17, 2016

\begin{abstract}
The bond strength of methacrylate (Z350, 3M ESPE) and silorane (P90, 3M ESPE) restorations, using different cavity filling techniques, was investigated. Cavities $(6 \times 3 \times 3)$ in bovine teeth were filled using bulk, oblique, or horizontal increments. A pushout test was carried out after $24 \mathrm{~h}$. Data were statistically analyzed $(\alpha=5 \%)$. Methacrylate-based composites and the horizontal filling technique showed the highest bond strength values $(10.2 \pm 3.9$, $\mathrm{p}<0.05)$. Silorane-based composites showed no statistically significant differences regarding the filling techniques $(p>0.05)$.
\end{abstract}

Keywords: Silorane Resins; Dental Materials; Composite Resins.

\section{Introduction}

Alternative monomer formulations for dental composites have been proposed to reduce polymerization shrinkage and minimize the stress effects related to methacrylate-based materials. ${ }^{1}$ A low-shrinkage, silorane-based composite was introduced in an endeavor to reduce the development of stress at the tooth-restoration interface and to improve the clinical performance of restorations. Besides the composition of composites, the cavity filling technique is another factor that can influence shrinkage stress ${ }^{2}$ and potentially affect bonded restorations clinically. The incremental filling technique using oblique increments is accepted as the gold standard because it minimizes shrinkage-related stresses. ${ }^{3}$ However, it is not well documented whether silorane-based restorations are affected or not by the cavity filling technique. The aim of this study was to evaluate the bond strength of resin composite restorations bonded to dental cavities filled using three techniques (oblique, horizontal, or bulk filling) and methacrylate or silorane-based composites. The hypotheses tested were that bond strength would be dependent on (I) the incremental filling technique and (II) the type of resin composite tested.

\section{Methodology}

\section{Preparation of specimens}

Thirty bovine incisors were sectioned up to $3 \mathrm{~mm}$ below the cementoenamel junction. The roots were sectioned longitudinally into two halves. Standard cavities (top diameter $6 \mathrm{~mm}$, bottom diameter 
$3 \mathrm{~mm}$, height $3 \mathrm{~mm}$ ) were prepared in the sectioned roots by a single operator, with all cavity margins located in the dentin/cementum. Cavities were prepared using \#245 water-cooled carbide burrs at high speeds (SS White, Lakewood, USA), yielding a C-factor of 3.4. Cavities were distributed $(n=10)$ according to the composites tested (methacrylate: Filtek Z350; silorane: Filtek P90; 3M ESPE, St. Paul, USA) and to the filling technique (oblique, horizontal, or bulk increments).

A two-step, total-etch adhesive system (Adper Single Bond 2; 3M ESPE) was applied, according to the manufacturer's instructions. This system was selected for both composites based on D'Alpino et al. ${ }^{4}$ because, despite the need of a dedicated adhesive, methacrylate-based adhesives are effective in replacing the $\mathrm{P} 90$ primer when bonding the silorane composite to the dentin. The dentin was etched with $35 \%$ phosphoric acid for $15 \mathrm{~s}$, followed by rinsing with air/water spray for 15 seconds. After solvent evaporation for $10 \mathrm{~s}$, light activation was carried out for $10 \mathrm{~s}$ using a LED unit with $800 \mathrm{~mW} / \mathrm{cm}^{2}$ irradiance (Radii; SDI, Melbourne, Australia). In the oblique technique, the first composite increment was inserted into the right cavity wall and into the left wall without contact with the previous increment, and then the central portion of the cavity was filled with two increments (four increments in total). In the horizontal technique, three increments extending from the right to the left were used. Each increment was light-cured for 20 seconds. For the bulk filling technique, a single increment was used to fill the cavity and light-cured for 60 seconds.

\section{Push-out test and failure analysis}

After storage in distilled water for $24 \mathrm{~h}$ at $37^{\circ} \mathrm{C}$, the push-out test was conducted on a mechanical testing machine (DL500; EMIC, São José dos Pinhais, Brazil), at a crosshead speed of $1 \mathrm{~mm} / \mathrm{min}$ until failure. Prior to mechanical testing, cavity dimensions were checked with a digital caliper accurate to $0.001 \mathrm{~mm}$ (Starret, Itu, Brazil). The test was performed by extruding the restoration out of the cavity. Push-out data were analyzed by two-way analysis of variance (composite type $\times$ filling technique) and all pairwise multiple comparisons were made using Fisher's LSD test $(\mathrm{a}=0.05)$. After the test, the specimens were observed at $40 \times$ optical magnification and failure modes were classified as adhesive (interfacial) failure or cohesive failure (cohesive within dentin or within composite). Descriptive statistics was used to report the failure data.

\section{Results}

Results for the push-out bond strength test and distribution of failure modes are shown in the Table. The factor 'filling technique' was not significant $(p=0.48)$, while the factor 'material' $(p=0.021)$ and the interaction between factors $(p=0.032)$ were both significant. Adhesive failure was predominant in all groups, with the highest frequency of adhesive failures observed for the silorane composite/horizontal technique and the lowest frequency of adhesive failures observed for the methacrylate composite/oblique technique.

\section{Discussion}

The results of this study provide evidence that the association between composite type and the

Table. Means (standard deviations) for push-out bond strength (MPa) and percentage of failure modes (\%)

\begin{tabular}{|c|c|c|c|c|c|c|}
\hline & \multicolumn{3}{|c|}{ Methacrylate composite } & \multicolumn{3}{|c|}{ Silorane composite } \\
\hline & \multirow{2}{*}{ Bond strength } & \multicolumn{2}{|c|}{ Failure mode } & \multirow{2}{*}{ Bond strength } & \multicolumn{2}{|c|}{ Failure mode } \\
\hline & & Adhesive & Cohesive & & Adhesive & Cohesive \\
\hline Bulk & 05.0 (1.9) A,b & 88.8 & 11.2 & $6.1(1.5) A, a$ & 88.8 & 11.2 \\
\hline Horizontal & $10.2(3.9) \mathrm{A}, \mathrm{a}$ & 71.5 & 28.5 & $4.9(2.1) \mathrm{B}, \mathrm{a}$ & 100 & 0 \\
\hline Oblique & $06.4(1.4) \mathrm{A}, \mathrm{b}$ & 42.8 & 57.2 & $6.0(3.0)$ A,a & 88.8 & 11.2 \\
\hline
\end{tabular}

Distinct uppercase letters indicate significant differences in the same row. Distinct lowercase letters in the same column indicate statistical differences; $p<0.05$ 
restorative filling technique may significantly affect the retention of restorations. Therefore, the two hypotheses tested were accepted. The differences in bond strength between materials and techniques are mainly related to the stress state inside the dental cavity during restorative procedures. Several factors may influence the magnitude of the stress generated by volumetric polymerization shrinkage of composites, including the modulus of elasticity ${ }^{5}$ and cavity configuration factor (C-factor). ${ }^{6}$ For the methacrylate-based composite, the results showed higher bond strength for the horizontal rather than the oblique incremental filling technique. Since standardized cavities were used for all restorations, this finding is likely an effect of the higher number of increments required to fill the cavity in the oblique filling technique. It has been shown that the light activation of each new increment and the heat generated tend to increase the total stress in the whole restoration, leading to higher stress at the bonded interface. Interestingly, more cohesive failures within the composite were observed for the methacrylate composite-horizontal technique combination.

The lower bond strength of bulk filling may be linked to higher shrinkage stress generated at the interface during polymerization, allowing locally-driven composite debonding from the dentin, decreasing retention. These results are in agreement with a previous study showing that contraction stress affects composite-to-dentin bonding, ${ }^{8}$ compromising the longevity of composite restorations. Regarding

\section{References}

1. Ilie N, Hickel R. Silorane-based dental composite: behavior and abilities. Dent Mater J. 2006;25(3):445-54. doi:10.4012/dmj.25.445

2. Park JK, Chang JH, Ferracane J, Lee IB. How should composite be layered to reduce shrinkage stress: incremental or bulk filling? Dent Mater. 2008;24(11):1501-5. doi:10.1016/j.dental.2008.03.013

3. Pilo R, Oelgiesser D, Cardash HS. A survey of output intensity and potential for depth of cure among lightcuring units in clinical use. J Dent. 1999;27(3):235-41. doi:10.1016/S0300-5712(98)00052-9 the silorane based-composite, there was no significant difference between the different filling techniques, probably because this composite has lower shrinkage, generating similar stresses at the interface for all restorative techniques. Overall, both materials presented similar bond strength values, although the higher values for the methacrylate-based composite suggest that composition of the material plays an important role in the bonding process. The silorane composite has higher modulus of elasticity and lower internal deformation, allowing lower plastic deformation and polymer relaxation, thereby decreasing retention. ${ }^{8}$ However, no significant difference between the bulk and oblique techniques was observed for any of the composites.

The present findings highlight the importance and relationship between material composition and filling techniques when restoring dental cavities. ${ }^{9}$ In this study, the same adhesive system was used for methacrylate and silorane-based composites in order to rule out the differences between adhesives. ${ }^{5}$ This was based on a recent study showing no incompatibility between the same adhesive used here and the silorane-based composite. ${ }^{4}$ In the clinical setting, it seems that the silorane-based composite is less sensitive to the restorative technique used than methacrylate-based materials.

\section{Conclusion}

The type of composite evaluated separately or associated with the filling technique affected the retention of composite restorations in dental cavities.

4. D'Alpino PHP, Farias NC, Silva MS, Goes MF, Miranda González AH, Di Hipólito V. Compatibility between silorane adhesive and simplified methacrylate-based adhesive systems. Dent Mater J. 2013;32(2):263-73. doi:10.4012/dmj.2012-245

5. Van Ende A, De Munck J, Mine A, Lambrechts P, Van Meerbeek B. Does a low-shrinking composite induce less stress at the adhesive interface? Dent Mater. 2010;26(3):215-22. doi:10.1016/j.dental.2009.10.003

6. Ferracane JL. Buonocore Lecture. Placing dental composites - a stressful experience. Oper Dent. 2008;33(3):247-57. doi:10.2341/07-BL2 
7. Bicalho AA, Pereira RD, Zanatta RF, Franco SD, Tantbirojn D, Versluis A, Soares CJ. Incremental filling technique and composite material--part I: cuspal deformation, bond strength, and physical properties. Oper Dent. 2014;39(2):71-82. doi:10.2341/12-441-L

8. Bouillaguet S, Ciucchi B, Jacoby T, Wataha JC, Pashley D. Bonding characteristics to dentine walls of class
II cavities, in vitro. Dent Mater. 2001;17(4):316-21. doi:10.1016/S0109-5641(00)00089-0

9. Hahnel S, Henrich A, Bürgers R, Handel G, Rosentritt M. Investigation of mechanical properties of modern dental composites after artificial aging for 1 year. Oper Dent. 2010;35(4):412-19. doi:10.2341/09-337-L 